\title{
Indígenas em Canarana: notas citadinas sobre a criatividade parque-xinguana
}

\section{Amanda Horta}

- Museu Nacional, UFRJ | Rio de Janeiro, RJ, Brasil

$\checkmark$ amandahorta@gmail.com

\section{RESUMO}

Este artigo propõe uma aproximação aos indígenas parque-xinguanos desde a cidade de Canarana (MT), município que compõe a porção sudeste do Parque Indígena do Xingu (PIX). Sediando as principais instituições de atendimento social, a FUNAI regional e diversas subsedes de organizações indígenas, Canarana é um município de referência para os indígenas do PIX. A cidade, espaço regido por uma lógica de Estado que insiste em reduzi-los à imagem do pobre, se faz cada dia mais um ambiente também indígena, desafiando a existência e a filosofia parque-xinguanas e dando origem a um momento absolutamente criativo da vida destas pessoas, de suas práticas filosóficas, de sua imaginação. Partindo de minhas experiências em Canarana entre os anos de 2014 e 2016, este trabalho explora duas diferentes imagens dos brancos da cidade formuladas pelos parque-xinguanos - o "peão" e o "chefe" - destacando as consequências da complexificação desta categoria para a teoria indígena das transformações no contexto urbano. Por fim, aborda os movimentos e expectativas indígenas quanto às suas relações na cidade e propõe uma reflexão sobre algumas das incongruências mais salientes entre a perspectiva parquexinguana e as formas com que o Estado pretende atualizar estas relações nas paisagens urbanas deste município. 
Os índios saíram da floresta e passaram

a descer nas áreas de produção.

- Ministra da Agricultura, Pecuária e Abastecimento,

sobre a os conflitos entre indígenas e o agronegócio no Brasil, em Janeiro de $2015^{1}$

Já faz muito que entre a floresta, paraíso intocado das terras indígenas, e as áreas de produção, futuro progressista deste país, não existe a tal ladeira ideal vislumbrada pela ex-ministra Kátia Abreu. O disparate, conhecido por aqueles que já lançaram uma breve mirada sobre a situação indígena no Brasil, não está apenas nas imagens equivocadas que ela aciona na frase e que foram felizmente criticadas por lideranças indígenas, pelos movimentos sociais e pela mídia - o suposto avanço imprudente dos primitivos sobre os civilizados-mas também em tudo aquilo que subjaz a seu discurso - o índio do museu de cera, em sua prisão de floresta, alheio a tudo em seu isolamento. Uma política de alheamento e de invisibilização, que historicamente usurpa a voz e a vida das populações indígenas.

Este artigo² versa sobre certos índios que, saídos da floresta - leia-se, de suas casas e aldeias no Parque Indígena do Xingu (PIX) -, demoram hoje em Canarana, sede do município mato-grossense que ocupa a região sudeste do PIX. A situação parque-xinguana não é inédita e os indígenas que residem em espaço urbano configuram números expressivos dos censos federais 3 . Ainda assim, como mostra Nunes (2010), a questão seguiu deixada de lado pela antropologia brasileira até as últimas duas décadas, quando etnografias sobre a situação indígena no espaço urbano começam a ganhar espaço ${ }^{4}$.

Se a cidade hoje é, muitas vezes, uma realidade indígena, esta realidade se coloca de múltiplas maneiras, sempre marcadas pelo encontro entre uma lógica de Estado, administrativa e burocrática, e uma gente indígena que subverte, sem pudor, essa lógica, para desespero daqueles que a tem como força maior. Assim, pôr-se a pensar com os indígenas na cidade é ter-se às voltas com as políticas iminentes da antropologia contemporânea: como fazer antropologia num universo em que o outro não resta perdido numa ilha do pacífico? Ou como fraseou Tânia Stolze Lima certa vez, como fazer uma antropologia da alteridade em presença?

\section{A CIDADE CHEGA ATÉ OS ÍNDIOS}

Muito antes dos parque-xinguanos ${ }^{5}$ chegarem às cidades do entorno e marcarem sua presença no meio urbano, as cidades já chegavam até eles. No final dos anos 40, o Xingu estava na moda. Fazia pouco, o governo Vargas criara a Fundação Brasil Central e a Expedição Roncador-Xingu para desbravar as regiões norte
1 Entrevista de Katia Abreu. Site da Folha de São Paulo. 05/01/15. Disponível em http://www1.folha.uol.com br/poder/2015/01/1570557nao-existe-mais-latifundiono-brasil-diz-nova-ministrada-agricultura.shtml último acesso: 10/03/15.

2 Uma versão preliminar deste artigo foi apresentada no 55 Congresso Internacional de Americanistas, ocorrido em julho de 2015 em El Salvador. Agradeço aos comentários e indagações dos presentes, em especial dos organizadores, Stephen Hugh-Jones, Geraldo Andrello e Antônio Guerreiro. Agradeço também a Katia Yukari Ono por ajudar a gestar essas ideias ainda nos tempos de Canarana.

3 Mesmo que entre os anos de 2000 e 2010 tenha havido um decréscimo populacional de indígenas no espaço urbano do país como um todo-com exceção da região norte-os números absolutos são ainda expressivos: mais de $300 \mathrm{mil}$ indígenas vivem hoje em áreas urbanas no Brasil (IBCE, 2010).

4 Nunes (2010) destaca, antes, o trabalho de Roberto Cardoso de Oliveira (1968) e quatro dissertações de mestrado defendidas no início dos anos 80 , sob sua orientação. A despeito desse início de fôlego, o assunto teria sido abafado nas duas décadas subsequentes, voltando a ressurgir na década de 2000 .

5 Para designar os indígenas provenientes do PIX cunhei o termo parque-xinguanos. $\mathrm{Na}$ bibliografia firmou-se chamar 
e centro-oeste e abrir a senda do progresso pela fixação de brasileiros naquelas áreas. A Força Aérea Brasileira (FAB) instala uma base no alto Xingu, para servir de entroncamento para rotas da aviação intercontinental e a imprensa divulga a grande obra civilizatória empreendida pelo governo na região. Parlamentares, jornalistas e militares visitam as terras dos índios, valendo-se da infraestrutura criada pela $F A B$ e da propaganda garantida pela cobertura da imprensa, que usa de apelos patrióticos em publicações sobre a urgência da preservação da diversidade cultural e ecológica encontrada naquele território. A proposta de criação do Parque do Xingu ${ }^{6}$ se popularizava na imprensa e arregimentava também algumas personalidades políticas.

Ao mesmo tempo em que as pressões para a criação do Parque aumentavam, e que a opinião pública se mobilizava em torno da ideia deste paraíso verde, a onda especulativa varria o Mato Grosso. Com o fim do Estado Novo de Vargas, em 1945, o mercado de terras públicas chega a seu ápice. O encontro com os indígenas e a proposta de criação do Parque, só aumentam a especulação e o incentivo do governo do MT para a venda das terras - na esperança de que, transformadas em reserva, fossem indenizadas depois, pelo governo federal. Neste contexto, ainda nos anos 40 , as primeiras empresas agrícolas chegam ao MT com fins colonizatórios ${ }^{7}$. O movimento ganha força nos anos 70 com a política de ocupação da Amazônia, implementada na ditadura militar, que incentiva assentamentos de colonos gaúchos na região centro-oeste por meio de projetos fundiários. Nesta segunda leva se inclui a cidade de Canarana, foco deste trabalho, que se origina com um núcleo de colonização que instala seus primeiros agricultores em 1972 e que em 1979 se emancipa como município. Canarana, que abrange uma pequena porção à sudeste do PIX, é hoje a principal via de acesso às aldeias localizadas na parte sul da reserva.

A criação do PIX é um passo a mais no processo de progressiva sedentarização das populações parque-xinguanas, isto é, de sua fixação em uma área imposta pelo Estado nacional sob a prerrogativa de assegurar a elas um território restrito e isolado. Antes mesmo do reconhecimento oficial da reserva, a segurança de suas fronteiras era posta à prova, pois as epidemias de gripe e sarampo - trazidas pelos brancos, claro-atingiam os grupos indígenas dentro de seu próprio território. Grupos que viviam no entorno, em situação demográfica extremamente fragilizada pelas guerras com outros povos e pelo avanço das frentes de contato são transferidos para o PIX pelos irmãos Villas Bôas ${ }^{8}$. Dentre eles, vivem ainda no Parque, os Kawaiweté, os I kpeng e os Kisêdjê, todos transferidos entre a segunda metade da década de 60 e os primeiros anos da década de 70. Na época, várias aldeias parque-xinguanas, com seus contingentes populacionais fortemente abalados, aproximaram-se dos postos de assistência do Serviço de Proteção ao Índio (SPI) e depois da Fundação Nacional do Índio (FUNAI), xinguanos, os indígenas da região dos formadores do rio Xingu, que habitam a parte sul do parque e que se integram num sistema pluritétnico e multilíngue de trocas assim assado. No sentido hidrográfico, xinguanos seriam todos aqueles que vivem as margens do rio Xingu. Como não digo exclusivamente de uns, nem inclusivamente de outros, optei por este termo que integra o sistema pluriétnico e multilíngue do Alto Xingu, na parte sul do Parque; e grupos indígenas localizados mais ao norte, bastante heterogêneos, que não compõe este sistema social, mas que habitam também o PIX

6 O que chamamos hoje Terra Indígena Xingu nasce com o nome de Parque do Xingu, com ênfase no objetivo de se preservar, a um só tempo, os indígenas e a natureza que eles habitavam (Menezes, 2000).

7 "Por colonização compreendia-se: abertura de estradas, construção da sede da colônia, loteamento e colocação na gleba dos primeiros agricultores" (Menezes, 2000 :182).

8 Os irmãos Orlando, Cláudio e Leonardo Villas-Bôas participaram das primeiras atividades da Expedição Roncador-Xingu, chefiando-a depois. Orlando foi também o primeiro administrador do Parque. 
firmando a aliança que tinham com os Villas-Bôas e abastecendo-se de bens brancos, tanto materiais, quanto imateriais. Orlando ensinava alguns indígenas a escrever em português, a fim de "prepará-los, com a orientação de, no futuro, desempenharem funções" administrativas no Parque (Menezes, 2000: 283). A $F A B$ admitia alguns soldados indígenas. $O$ mundo dos brancos se fazia presente dentro das terras do PIX e a instalação dos postos administrativos e de assistência, as fronteiras, as escolas, vêm se juntar às tantas outras tentativas de fixar as vidas indígenas. No Brasil ${ }^{9}$, hoje e antes, a diferença ou se anula com integração ou se omite com isolamento - em todo caso, o Estado põe-se a fixá-la.

Se o mundo do branco chegava por dentro do PIX, pela base aérea, pelos postos e pelas doenças, ele também vinha de fora, com o avanço da fronteira agrícola e o desenvolvimento econômico do Mato Crosso. Em nossos encontros em Canarana, Pirakumã Yawalapiti, irmão do grande cacique Aritana, costumava me dizer que, quando da criação do PIX, parecia um desvario imaginar que a dita "civilização" pudesse um dia chegar até eles. Era como se o Parque não tivesse beira. Hoje, a profecia anunciada pelos brancos se cumpriu e a soja engoliu a floresta densa: a fronteira agrícola pressiona os limites do Parque e a soja termina na linha exata em que começa a reserva.

As consequências disso são enormes. A deterioração das cabeceiras dos formadores do rio Xingu, assim como as mudanças climáticas estão ambas diretamente relacionadas com o avanço da fronteira agrícola e com a degradação de áreas adjacentes à Terra Indígena. Elas trazem alterações ao regime de fogo e de chuvas, que afetam os ciclos agrícolas e as práticas tradicionais de cultivo, assim como os regimes de pragas, de peixes e outros animais da fauna local (Schwartzman et al., 2013). Além disso, como em toda Terra Indígena, a área demarcada se revela escassa e se desgasta com o uso. A população indígena cresce, o limite da TI fixa, e a exploração tradicional, mas reincidente-os índios não têm mais para onde ir-, dá indícios do esgotamento dos recursos naturais. O Estado se esforça em fazer das fronteiras da $\mathrm{Tl}$, um verdadeiro cárcere indígena. Isolamento ou integração. Mas, "você sabe, sempre se diz 'das duas, uma', e há sempre uma terceira coisa" (Lévi-Strauss apud Viveiros de Castro, 2009: 196).

\section{II. os ÍNDIOS VÃo ATÉ A CIDADE}

O surgimento de Canarana se inicia em 1972, quase dez anos depois da homologação do PIX, em 1961, quando todos os povos que habitam hoje a reserva já estavam ali alocados. Desde o princípio, o Parque vinha sendo administrado pelos valores e pela mão firme do sertanista Orlando Villas-Bôas, que tinha por intuito "defender [os indígenas] de contatos prematuros e nocivos com as frentes de ocupação da sociedade nacional" (Villas-Bôas e Villas-Bôas, 1975: 9).
9 Não apenas no Brasil. Como demonstram trabalhos como os de Kelly (2011), Pitarch (2010) e West (2006), as políticas indígenas no mundo todo parecem assumir a alteridade como subversiva da ordem. 
O histórico de contato do Xingu é, portanto, bastante peculiar. Os primeiros encontros sistemáticos entre os povos parque-xinguanos e os brancos foram mediados pelos irmãos Villas-Bôas, não por bandeirantes, fazendeiros, garimpeiros ou missionários. Kanawayuri Kamaiurá relata a relação de seu povo com os irmãos indigenistas, destacando os esforços que faziam para resguardar os indígenas, o quanto pudessem, dos males da civilização:

\section{O contato do povo Kamaiurá com os brancos foi uma fase difícil. Quando os Kamaiurá viram objetos novos como chapéus, roupas, cobertores, botas, redes, miçangas, facões, machados e sabões, queriam todos esses objetos para eles. Mas Orlando [Villas-Bôas] não dava essas coisas para qualquer pessoa, ele só entre- gava a cacique de cada aldeia para ele fazer distribuição. (...) Orlando foi muito rigoroso na sua administração. Ele não deixava os Kamaiurá usarem roupa dizendo que era para não acabarem os costumes, as festas. Permitia só o uso de anzol, linha, fósforos, ferramentas e algumas coisas (Kamaiurá, 2011: 49).}

Quando Orlando deixa a administração do Parque, em 1974, o isolacionismo protetor instituído por ele e seus irmãos ${ }^{10}$ perde sua força, e mais indígenas passam a visitar as cidades do entorno, às vezes até as metrópoles, Rio de Janeiro, São Paulo, Brasília. A viagem até as cidades é longa e dispendiosa, mas a curiosidade é muita e a possibilidade de vender alguns itens da roça e do artesanato local, entusiasma os parque-xinguanos. Ali eles veem os brancos, escutam sua língua difícil, suas músicas animadas, provam suas comidas, suas bebidas, aguçam seus desejos e gastam tudo que têm: retornam com sal, açúcar, café, balinhas e um ou outro bem de consumo mais durável.

Os administradores que sucederam os Villas Bôas se dedicaram a suprir as aldeias de uma estrutura básica que permitisse um atendimento mais sistemático à saúde, dando-lhes rádios de comunicação e barcos a motor, destinados ao transporte de pacientes. Tal estrutura mínima permitiu que, aos poucos, o que antes era um trânsito ocasional, se tornasse um caminho corriqueiro, pois os barcos e aviões que atravessam doentes também levam acompanhantes e, sempre que há espaço, algum outro indígena aproveita a carona no transporte da saúde. Ademais, nos anos 90 surgem os primeiros caminhos que ligam, por terra, o centro urbano de Canarana ao rio Culuene ${ }^{11}$ (Rodarte, 2010). O trânsito com a cidade, que já era progressivo desde a saída dos Villas Bôas da administração do PIX, se impulsiona com a nova facilidade. Os indígenas chegam até a cidade e não há passe de mágica que os torne brancos neste romper de fronteira: nem integrados, nem isolados, os indígenas passam a compor o espaço urbano.

A época da abertura dos primeiros caminhos é também o início do desenvolvimento econômico e estrutural desta cidade planejada, passando do "mato"
10 Sobre a política administrativa dos irmãos Villas-Bôas no Parque Indígena do Xingu ver Menezes (2000) capítulo 12 :273-94.

11 Ao longo do rio Culuene, um dos formadores do rio Xingu, se estende uma porção de aldeias de índios falantes de línguas karib, que integram o sistema pluriétnico e multilíngue do Alto Xingu. Os alto-xinguanos são, sem sombra de dúvida, os principais usuários destes caminhos por terra. 
de antes - os primeiros colonos chegam apenas em 1972-, às largas avenidas asfaltadas de agora. Em 2010, a reestruturação da FUNAI e a demanda parque-xinguana por um acompanhamento mais próximo de suas questões, leva a Coordenação Regional da FUNAI Xingu a ser transferida de Brasília para Canarana, incorporando em seu quadro de funcionários um número ainda maior de servidores indígenas. Como consequência, vários indígenas parque-xinguanos se estabelecem neste município, quase sempre acompanhados de seu núcleo familiar - e muitas vezes de membros da família extensa-, ocupando cargos na FUNAI que, idealmente, prezam antes pela indianidade de seus contratados, que pela sua integração à lógica de Estado ${ }^{12}$.

O movimento dos indígenas em direção a Canarana coincide também com o declínio da assistência paternalista prestada pelo SPI e continuada pela FUNAI quando da extinção deste primeiro órgão, que se oficializa com a reestruturação da FUNAI (Decreto $n^{\circ} 7,056$, de 28 de dezembro de 2009). Assim, na última década, as relações entre indígenas parque-xinguanos e fazendeiros, madeireiros e turistas, parecem tentar atualizar, sem muito sucesso, as relações paternalistas outrora entretidas com os órgãos indigenistas oficiais. Tempty Suyá relata essa difícil transição:

Meu povo diz que apesar dele [Orlando Villas-Bôas] contatar os índios e reconhecer a área junto ao governo brasileiro, ele acostumou os índios com o paternalismo, com presentes. Por isso até hoje em dia há pessoas no Xingu que querem ganhar presentes dos brancos (Suyá, 2011: 48-9).

O fim destas relações em que o branco legitima sua autoridade por meio de concessões generosas - ou pelo menos seu considerável declínio-impele os parque-xinguanos em direção à crua lógica estatal, um universo burocrático do qual vinham sendo protegidos. Dentre as regras e procedimentos que se impõe no intuito de lhes reger a vida, estão os tantos documentos que passam a ser-Ihes indispensáveis: carteira de identidade, CPF, título de eleitor, carteira de trabalho. Eles devem se registrar no Cadastro Único (Cadúnico) para ter acesso aos benefícios dos programas sociais do governo federal e estadual. Para tal, precisam abrir uma conta no banco e às vezes certificar a matrícula escolar dos filhos. Se reside na aldeia, o indígena precisa então solicitar a um funcionário da FUNAI que the redija um documento, atestando a veracidade da sua alegação de residência, pois o que comprova no mundo branco, não é a palavra, mas o papel: uma conta de água, de luz, que eles obviamente não têm³ .

No ano de 2014, passei boa parte dos meus dias no Centro de Cultura e Convivência (CCC) da cidade de Canarana, espaço mantido pela FUNAI que funciona como uma casa de apoio para os indígenas alto-xinguanos. Equipado
12 Esta é uma das questões mais delicadas dentro da FUNAI Canarana. Ao mesmo tempo em que esta instituição opta por ter indígenas em seu quadro de funcionários, sob o pretexto de nutrir-se da diferença que eles possuem para melhor informar suas políticas, existe um mal-estar aberto por parte funcionários brancos da instituição em relação aos funcionários indígenas, devido à sua suposta incapacidade de realizar tarefas dentro dos critérios brancos de produtividade e resultados. Os brancos se incomodam com a demora das reuniões, com a distribuição supostamente apressada de recursos para gasolina, construção de casas, e outras solicitações pessoais (não comunitárias), incomodam-se, sobretudo, com a dificuldade dos funcionários indígenas em prestar contas, fazer relatórios e seguir uma agenda rígida. Um paradoxo: índios são contratados por serem índios, mas avaliados como se devessem ser brancos. Questões como essas rondam todos os indígenas que ocupam cargos em instituições indigenistas na cidade, sobretudo as instituições do Estado. Os parque-xinguanos não sabem muito bem como se portar nessas situações e se interrogam sobre como lidar com as expectativas de seus chefes e colegas de trabalho não-índios e dos indígenas do Parque a respeito de seu trabalho.

13 Para um debate sobre os documentos a partir de um caso nos Estados Unidos, ver Peirano (2009) 
com um rádio de comunicação, o CCC é frequentado não apenas pelos indígenas do alto Xingu em trânsito, mas por qualquer um que deseje falar pelo rádio com as aldeias. Ali também funciona o setor da FUNAI responsável por auxiliar os indígenas nas questões de previdência social, que atende todos os povos do PIX. Numa manhã de maio, presenciei um homem kawaiweté solicitar no CCC a troca de nome da sua filha. O nome que constava na identidade da menina, afirmava o pai, era um nome de criança, e ela já estava prestes a completar 13 anos: era hora de trocar de nome. A funcionária da FUNAI indignava-se. Ela dizia que não havia o que fazer: o papel não erra, o nome não muda. E completava afirmando que mudar de nome é coisa de vagabundo, de quem tenta "passar-se por duas pessoas" para ganhar dois benefícios sociais. Quando a porta da sala se fechou pela terceira vez, a solicitação pela troca do nome da filha definitivamente recusada, o homem viu que eu acompanhava a cena e passou a me dizer que a menina, já grande, não era mais chamada pelo nome da identidade, e que ele apenas desejava ajeitar as coisas.

A intenção do indígena era garantir a correspondência entre o documento e seu portador - a filha -, numa clara demonstração de que ele compreendia a regra do jogo da identificação: a redundância entre o que o documento diz e o que a pessoa é, é um de seus traços essenciais (Peirano, 2009). Mas uma regra anterior, obviada na situação e aparentemente desconhecida pelo indígena kawaiweté, conspira pelo caráter definitivo e imutável do prenome. Entre os brancos, o nome estabiliza. $O$ Estado não permite a existência de sujeitos não regulados e assertoa que se os índios desejam entrar, um pouco que seja, no mundo dos brancos, devem deixar-se reger pela lógica estatal de nomes estáveis e imutáveis. O Estado impõe um molde branco e sedentário para a identidade indígena e clama, nas entrelinhas, que em seu seio não há espaço para a diferença.

Contrariando o grito estatal, o nome no documento é, muitas vezes, uma ficção para amansar a burocracia; o comprovante de residência também. Tanta gente indígena passa a ser chamada por um nome distinto daquele que consta na identidade e tanta gente muda de aldeia, a despeito do comprovante que leva em mãos. Mesmo driblada, a noção de uma identidade rija reclama seu espaço na máquina estatal, que se aplica a fixar os indígenas, identizá-los e, disfarçada na boa intenção de salvá-los, estabelece outra vez a lógica binária que concebe a indianidade apenas em integração ou isolamento. Para ter benefícios é preciso ter documentos, pôr os filhos na escola, saber a data e a hora exata em que nasceram, ter papel e caneta à mão para anotá-las quando do acontecimento e saber fazê-lo. É preciso ir à cidade solicitar os benefícios e regularizá-los de três em três meses, com novas idas à cidade. Mais que tudo isso, é preciso usufruir destes benefícios, gastar o dinheiro, obter bens, serviços, tal como fazem os brancos. 
A presença de instituições de assistência nas aldeias, das coordenações da FUNAI, do serviço de saúde e de algumas sedes de associações, assim como o avanço da fronteira agrícola e a limitação de seus espaços produtivos tradicionais, faz com que os indígenas tenham cada vez menos recursos de movimento. É certo que os grupos parque-xinguanos são sedentários e, entre os alto-xinguanos, evidências arqueológicas remetem esta característica aos tempos pré-históricos (Heckenberger, 2011). Contudo, se as aldeias são relativamente fixas, não há dúvidas de que a vida indígena nada tem de estática e que existem ainda muitos fatores capazes de desencadear nos parque-xinguanos o pulso do movimento.

\section{OS BRANCOS SÃO MUITOS}

A intensificação das relações entre os indígenas e os brancos e a aproximação entre os parque-xinguanos e as cidades do entorno nas últimas décadas, narradas nas seções anteriores, acarretaram uma série de inflexões nas imagens que os parque-xinguanos fazem dos não-indígenas. A sede do município de Canarana, sobretudo, espaço focal deste trabalho, coloca um contexto relacional bastante específico de operação destas imagens. Entramos aqui no terreno das teorias amazônicas sobre o encontro com os brancos, modelos desenvolvidos junto aos indígenas, por pesquisadores comprometidos com a perspectiva dos índios. Esta antropologia com a qual este trabalho se vincula, toma as teorias nativas sobre as experiências interétnicas como base de suas reflexões. Autores como Gow (1991) e Vilaça (2000) aliaram-se à perspectiva de seus interlocutores indígenas e inauguraram uma leva de trabalhos interessados em colocar a teoria amazônica "à prova das circunstâncias modernas", buscando respostas teóricas para os cenários interétnicos que estivessem à altura das teorias ameríndias desenvolvidas em contextos tradicionais (Kelly, 2005: 202).

Nos últimos anos, contribuições de fôlego vieram acrescer esta agenda. Kelly (2009) propôs uma teoria nativa do contato na Amazônia, analisando as relações entre os Yanomami do rio Ocamo a partir de uma declaração comum entre estes e tantos outros povos indígenas do oeste amazônico: "agora somos civilizados". O argumento de Kelly é que, se para os agentes não-indígenas que atuam na região a afirmação era signo da degradação cultural desses povos, para os índios, sujeitos enunciadores deste discurso, virar branco era um movimento de diferenciação dentro do universo yanomami, que apontava para a dualidade eu/outro operante nas ontologias ameríndias. "[N]apë (branco) é um conceito estritamente relacional, que se refere ao modo como uma pessoa ou grupo se coloca face a outro", sublinha Kelly (2005: 209). Assim, as transformações em contextos de contato não dariam origem a uma fusão entre as duas identidades em jogo - fundando um mestiço, nem completamente branco, 
nem completamente indígena - mas a uma dialética entre os feixes de afecções que os definem (Kelly, 2011: 220).

Os Yanomami se fazem plenamente brancos e plenamente indígenas, em circunstâncias distintas, conclui. A linguagem teórica deste argumento retoma o simbolismo de Wagner (2010 [1981]), que entende a ação humana como fundamentada numa dialética entre aquilo que os sujeitos entendem como pertencendo à convenção, às regras estabelecidas, ao dado, e àquilo que eles entendem como pertencendo à inovação, produto da agência histórica, que cabe aos sujeitos construir ativamente. Os coletivos extra-modernos ${ }^{14}$, afirma Wagner, costumam assumir o parentesco, a moralidade, a língua, como atributos pertencentes à ordem do dado, e a cultura, como construída - coisa que ocorreria da maneira inversa entre os euro-americanos (Wagner, 2010 [1981]). A dialética que Kelly descreve opera uma relação figura-fundo entre aquilo que é tomado pelos Yanomami como dado e como construído no contexto de suas relações interétnicas, seja com os brancos, seja com outros indígenas. Neste argumento, quando numa relação, o Yanomami tem de construir afetos brancos para si, sobre o pano de fundo dado da sua indianidade, temos o fenômeno indígena chamado virar-branco ${ }^{15}$; quando a convenção do contexto é o caráter branco de sua pessoa e o indígena deve construir ativamente seus afetos índios, o fenômeno é chamado virar-índio.

O trabalho de Nunes (2012) em Buridina (CO) junto aos Karajá, também se nutre das noções wagnerianas de invenção cultural e de suas ressonâncias em outros modelos da socialidade amazônica, como o do parentesco e da pessoa ${ }^{16}$. Seguindo a trilha de Kelly, Nunes mostra como, entre estes Karajá, a parte branca da pessoa pode figurar ora como um todo dado, ora como um todo construído, dependendo do contexto de contraste. A possibilidade de alternar a direção da construção de seus afetos, agregando potências em ambas as posições, é fundamental aqui. Em Buridina, a ênfase do discurso dos Karajá estava na importância de não se deixar fundir o lado indígena e o lado branco da pessoa, de não se virar-branco e índio ao mesmo tempo - sob o risco de enlouquecer e pôr-se então, como dizia um interlocutor de Nunes, a "pescar no asfalto" (Nunes, 2012: 97-8). Em Canarana, por sua vez, o discurso parque-xinguano insiste em outras questões, que abrem outros caminhos analíticos. Os indígenas do PIX destacam, na cidade, que o espaço da invenção - seja de sua branquitude, seja de sua indianidade-demanda uma diferenciação apurada dos afetos. Os fenômenos do virar-branco e do virar-índio, em Canarana, colocam, pois, uma questão suplementar: o tipo de branco ou de índio em que se está virando.

O PIX é composto por 16 povos distintos, falantes de línguas jê, aruak, karib e tupi, além de uma língua isolada; povos que a despeito da proximidade imposta pelo limite da terra indígena que compartilham, constroem ativamente suas
14 Recentemente, num projeto que propunha uma análise fina do livro de Latour, Enquete sur les modes d'existence, Viveiros de Castro apontou que "[A] noção de não-moderno (...) tende a assumir irresistivelmente um viés evolucionista que a torna sinônima de pré-moderno, primitivo, atrasado, tradicional, ou, como se dizia nos velhos tempos, subdesenvolvido. O prefixo extra-, assim, marca exterioridade, não superlatividade (como se se pretendesse "compensar" a conotação privativa do conceito de não-moderno), em relação ao regime ontológico (re) descrito por Bruno Latour nessa antropologia dos Modernos que é a Enquête" (Viveiros de Castro, 2015b: 2). Em The invention of culture, de 1975, Roy Wagner não diz de extra-modernos, tampouco de não-modernos ou pré-modernos. Wagner refere-se a essas populações como "sociedades tribais", termo usual na época, mas que passou já por uma crítica de teor muito similar à de Viveiros de Castro supracitada: "tribo" seria uma reminiscência do vocabulário evolucionista do século XIX um conceito que traria o ranço da inferioridade evolutiva atribuída a essas populações.

15 Optei por grafar o virarbranco com hífen, ainda que Kelly não o faça, para enfatizar que essa é uma forma de se transformar e não uma transformação neutra com resultado específico. $\mathrm{O}$ hífen pretendeu contaminar um pouco mais o verbo "virar" com o nome que lhe companha, e vice-versa, pois a diferença entre virar-branco e virar-o-quequer-que-seja, não está apenas naquilo em que o sujeito se transforma, mas no processo mesmo de transformação em que ele se engaja.

16 Ver, por exemplo, Viveiros de Castro (2002) e Vilaça (2015). 
diferenças e sua autonomia. As diferenças entre os índios são construídas pelo corpo, pela língua, pela dieta, pela estética ritual, pelo corpus mitológico, pelas normas do parentesco - fatores que Wagner associou ao universo da convenção dos coletivos extra-modernos, mas que, no jogo figura-fundo entre invenção e convenção, aparecem, em muitos contextos, como aquilo que cabe aos parque-xinguanos construir ativamente. Isso tudo, a que eles chamam costume, diferencia os índios entre si. O costume é, para os parque-xinguanos, algo que alguém "está acostumado a", e vem associado a um lugar. O espaço é um importante estabilizador de perspectivas (Nunes, 2012: 238-75): um sujeito acostuma-se a um lugar, pois este lugar implica um costume específico aos seres que o habitam.

Os humanos da cidade também se caracterizam por corpos, línguas, dietas diferentes entre si. Dentre os funcionários do ISA que vivem em Canarana, há alguns vegetarianos que, para espanto dos indígenas, recusam até mesmo peixe, além de uma moça de descendência japonesa, que já se aventurou a comer peixe de rio cru com pauzinhos que ela mesma esculpiu. Suas línguas se enrolam em sotaques do interior de Minas e São Paulo, sua pele é morena de sol. Eles são poucos, mas os indígenas os conhecem bem. Os gaúchos da cidade, por sua vez, frequentam as churrascarias e enchem seus pratos de carne de boi, mistura e salada. Falam com o acento puxado das terras do sul, tem os corpos brancos, os olhos e cabelos claros. Os nordestinos são uma gente de pele negra ou morena escura, de cabelos mais crespos, e diferente dos dois primeiros, não costumam frequentar os restaurantes. Como estes esparsos exemplos demonstram, os brancos se diferenciam sim pelo corpo, pela língua, pela dieta. No entanto, o que marca as diferentes condições de branco em Canarana é não é um afeto da mesma ordem daquele que diferencia os índios: o principal marcador da diferença na cidade é o trabalho, ocupação a que uma pessoa se dedica para conseguir dinheiro.

Independente da razão que leva o indígena do PIX à cidade, quase sempre é preciso trabalhar para permanecer ali. Os benefícios sociais geram uma renda ínfima a cada família, que mesmo se canalizada para uma única pessoa, pode não bastar para sustentar a vida na cidade. Em Canarana, os parque-xinguanos que não ocupam cargos nas instituições voltadas para os interesses indígenas, como a FUNAI e o Distrito Sanitário Especial Indígena (DSEI), empregam-se geralmente na construção civil, na limpeza e jardinagem das ruas, e na lavoura, trabalhos que devem ser realizados sob o sol, das 9 às $18 \mathrm{~h}$, sem descanso. $\mathrm{O}$ trabalho braçal não molda a língua, nem aguça os ouvidos para o português; não permite aprender as regras "do papel", grande arma da política dos brancos; demanda pouco trejeito social específico à cidade e dá pouco acesso aos bens tão desejados, pois paga mal. Trabalhar sem trégua sob o sol é, pois, para eles, o pior dos cenários: um trabalho de "peão", um sofrimento. 
Para os parque-xinguanos, a condição de peão não agrega potências capazes de render ao sujeito nenhum tipo de prestígio, não aumenta o alcance de sua voz, não faz brancos nem indígenas Ihe escutarem, quão menos seguirem seus passos. As expectativas das comunidades em relação aos indígenas que vão para a cidade é que eles possam conhecer os modos de relação dos brancos chefes, moldar a boca para língua portuguesa, aprender o que os brancos escondem em suas palavras para além de seus significados literais, saber usar os papéis, e apenas trabalhos que proporcionam saberes desse tipo são valorizados. $O$ índio que na cidade se posiciona como peão tem menos chances de voltar para a aldeia com mais prestígio do que quando saiu, pois ele não vive algo que o permita ajudar a comunidade depois, nos contatos hoje inevitáveis com a sociedade dos brancos. A imagem que os indígenas fazem do peão é daquele que sofre e nada mais. Mas essa não é a única posição social que a cidade apresenta. Há também os chefes, os doutores, pessoas que trabalham usando da palavra falada e da palavra escrita, com computadores e documentos, tudo isso sentados em sua sala climatizada. Estes fazem relações com outros chefes e pessoas influentes, diante de quem se colocam em posição de simetria.

É importante destacar que se o trabalho é o marcador da diferença entre o peão e o doutor, o valor deste marcador é puramente relacional. A má avaliação que os indígenas fazem do peão não se deve ao trabalho que ele exerce, mas ao contexto em que este trabalho é realizado e à posição social que ele implica. Roçar não é algo intrinsecamente ruim; capinar, jardinar, tampouco. Na aldeia, todos os homens, a despeito de sua posição na escala de prestígio, realizam atividades como essas. Exercidas na cidade, entretanto, essas atividades se tonam signo de sofrimento. $O$ peão se submete ao sol e aos mandos de um patrão duplamente branco, não-indígena e não-queimado de sol, e o que ganha com isso não o permite se colocar em posição de simetria com o seu chefe. Os indígenas estão seguros de que alguns não-indígenas, os "chefes" e os "doutores", trabalham apenas sentados numa cadeira grande dentro de uma sala com ar condicionado e que ganham muito mais dinheiro, prestígio e conhecimento para tal. A oposição relevante aqui, portanto, não é aquela entre o peão e o indígena aldeado, mas entre o peão e o chefe, duas imagens de branco que se rivalizam nos contextos relacionais citadinos em que o virar-branco está em pauta. É apenas no contexto indígena de produção ativa de devires-brancos que o virar-peão e o virar-chefe ou doutor podem emergir.

Sendo puramente relacional, para um parque-xinguano, a posição de "peão" não é exclusiva ao sujeito de labutação pesada. Se no trabalho, sob o sol quente, o indígena sofre, ele de fato ocupa a posição de peão. Mas a despeito do trabaIho que realiza, se em sua casa na cidade, o parque-xinguano sente fome de beiju ou de farinha, alimentos tradicionais no PIX, e não pode se saciar, ele sofre 
também; ele ocupa uma posição de peão. Conheci alguns brancos que recebiam jovens parque-xinguanos em suas casas, enviados por sua família para que pudessem estudar nas escolas públicas de Canarana. Seus pais aldeados, entregavam a estes brancos uma quantia previamente combinada, ou o cartão de seus benefícios sociais, em pagamento pela estadia do jovem estudante. Se o branco em questão não lhe cuida e lhe explora, o jovem parque-xinguano se vê numa posição de peão. A marca do peão é o sofrimento e a falta de autonomia sobre si: a incapacidade de saciar a fome por beiju, de adquirir os bens que deseja, de mudar seu destino, de optar por ficar à sombra. Tanto o sofrimento quanto a autonomia, são, obviamente, apenas uma perspectiva possível sobre a vida-a posição é instável, e aqueles que sofreram, podem, em outros contextos, assumir outras perspectivas sobre si. Sempre que, a despeito de sua ocupação laboral, o indígena assume a posição de falante de português (em oposição a alguém que não o é), de usuário das benesses da cidade (em oposição a um indígena aldeado), de estudante do sistema branco de ensino (em oposição a quem frequentou apenas a escola indígena, ou nem mesmo ela), ele ocupa uma posição de doutor.

Alguns meses depois da morte de um grande chefe yawalapiti, seus parentes começaram a organizar o ritual funerário intertribal do quarup, para qual seria necessário farto financiamento: convidaram todos os povos do PIX e diversos povos de outras terras indígenas. Sua filha tomou as rédeas da produção da festa: casada com um homem kawaiweté funcionário da FUNAI, ela vive na cidade há muitos anos, onde tem uma loja de artesanato indígena. Falante de bom português, engajada na defesa dos interesses de seu povo e no resgate da língua yawalapiti ${ }^{17}$, a moça passou a se articular para conseguir o dinheiro necessário para a festa, sobretudo para pagar o transporte dos convidados até a aldeia. Seu pedido de financiamento foi recusado pela FUNAI Canarana, onde o próprio marido da moça trabalhava. A filha do falecido, então, usou de suas relações e contatos para agendar uma reunião diretamente com o ministro da Cultura e o presidente da FUNAI, em Brasília. O ministro e o presidente, chefes brancos importantes, receberam-na pessoalmente e concederam o financiamento para a festa, algo que foi tomado com muita admiração pelos indígenas na cidade. Fazer relações com os chefes dá acesso a um universo que os indígenas do PIX desejam arduamente. A moça yawalapiti nada tinha de peão, ela se portava simetricamente aos brancos em suas relações.

Colocar-se em posição de simetria com os chefes e os doutores brancos engrandece, prestigia, e aquele que ocupa essa posição pode voltar à aldeia e ajudar a comunidade com suas relações. As experiências na cidade desencadeiam uma série de transformações nas pessoas parque-xinguanas e neste cenário citadino a intenção dos indígenas não é ser chefe à maneira branca-o que se espera é ser chefe branco à maneira indígena, igualmente poderoso e
17 De acordo com o site Povos Indígenas no Brasil, "A língua yawalapiti pertence à família Aruak, assim como as línguas mehinako e wauja, também faladas no Parque. Atualmente, apenas quatro ou cinco indivíduos falam yawalapiti, predominando na aldeia as línguas kuikuro (da família Karib) e kamaiurá (da família Tupi-Guarani), em razão dos muitos casamentos que ligam os Yawalapiti a esses grupos". (Disponível em: https:// pib.socioambiental.org/pt/ povo/yawalapiti/1193, acesso em dezembro de 2015). 
autônomo. A condição da paz entre os distintos povos do PIX, e também entre índios e brancos, é a autonomia entre as partes. Havendo uma assimetria explícita entre "peões" e "doutores"/"chefes", a relação que se instaura entre eles é necessariamente uma relação de predação, de guerra, na qual a perspectiva de um, do predador, se impõe à perspectiva do outro, sua presa; na qual apenas um dos sujeitos pode manter sua autonomia. O peão nada mais é que um porco para o chefe onça. A criatividade parque-xinguana toma como perfeitamente possível que a filha do chefe falecido, indígena, engajada, consiga se colocar em posição simétrica aos chefes brancos, sem predá-los, nem abrir mão, em momento algum, de sua indianidade. Sua posição não era de predadora, devoradora dos chefes brancos, mas de anti-presa ${ }^{18}$ : perigosa, autônoma e simétrica a estes. Assim, para virar-branco, virar-branco-chefe, claro, o pressuposto é que se seja indígena, algo que o Estado teima em não ver.

Um homem kawaiweté de cerca de 65 anos, com alguma proeminência política, conversava comigo certa vez sobre minha pesquisa. Dizia que a presença de indígenas do PIX na cidade de Canarana havia crescido muito nos últimos anos e que ele estava muito preocupado com esta situação. Falou que, na cidade, os indígenas só trabalhavam como peões e que ele via indígenas parquexinguanos na rua mexendo nos lixos-algo que eu vira poucas vezes ao longo de minha estadia em Canarana. Falou também que no carnaval os indígenas catavam latinhas e as vendiam por alguns trocados. O líder kawaiweté dizia sentir-se envergonhado com essa situação que, segundo ele, macula a imagem do indígena, fazendo com que os brancos pensem que são miseráveis. Era como se ele me dissesse: "os índios não são miseráveis!". O chefe kawaiweté bradava que ao contrário do que os brancos pensam, a miséria não define os índios do PIX; mas sua preocupação também refletia o fato de que, por portar-se assim, estes mesmos índios que não se definem pela miséria, faziam-se miseráveis da perspectiva dos brancos - uma situação bastante perigosa. Com este cenário ele não concordava. E continuava me dizendo que estes indígenas que se submetem a posições tão inferiores deveriam voltar para a aldeia, onde "tudo é de graça", em vez de permanecer ali naquela decadência. Os indígenas podem ir para à cidade e trabalhar como patrões, como médicos e advogados, "não tem problema", dizia ele. Mas para catar latas e remexer lixos, não. Se não se podem colocar numa posição simétrica à dos chefes brancos na cidade, melhor que retornem para a aldeia.

Para um parque-xinguano, a posição de peão é necessariamente ruim. Ela implica a ausência de autonomia sobre si, sobre seu corpo e sobre as transformações nas quais ele se engaja; implica o trabalho compulsório, que é como eles concebem todo trabalho regrado por terceiros, que não respeita o cansaço do corpo, ou o desejo de não o realizar quando assim quiser. Por isso, o chefe
18 A formulação é de Guerreiro e versa sobre os encontros rituais entre os diferentes chefes do alto Xingu. Segundo o autor, a "relação predador-presa, enquanto o modelo cosmológico de todas as relações sociais, tem uma forma peculiar de se atualizar no Alto Xingu. Aqui, ela também é o pano de fundo lógico por trás de qualquer relação: vê-se como sujeito quem assume a posição de predador. (...) Mas a especificidade xinguana é que os chefes estão mais para "anti-presas" do que para predadores de fato. $\mathrm{Na}$ atualização da relação virtual de predador-presa, os chefes, quando competem, talvez se vejam sob esta ótica, mas a forma dos cumprimentos de chegada e despedida e toda a etiqueta ritual em geral, são esforços no sentido de fazer das relações entre grupos (chefes) relações do tipo "predadorpredador". Apesar de estar virtualmente dada em qualquer relação, a posição de presa é intencionalmente obviada na produção de grupos autônomos que não guerreiam entre si" (2012: 397). Como demonstrei, esta é a forma por excelência dos encontros parquexinguanos - e não apenas altoxinguanos-com a alteridade branca na cidade de Canarana 
kawaiweté, dizia que os índios deveriam voltar se não conseguissem ser doutores. Parece óbvio para os indígenas do PIX que viver na cidade não é como viver na aldeia, que as atividades são outras e que isso tudo os transforma, na medida mesma em que viver, existir, é transformar. A ontologia ameríndia não toma o movimento da transformação como negativo, mas como inexorável, e o que define uma transformação como boa ou ruim é sua direção, seu vetor. O paradoxo está armado: o urbano, lugar de estabilidade, de nomes inalteráveis, de residência fixa comprovada, se apresenta aos parque-xinguanos como um novo contexto para suas transformações.

\section{SOBRE UM ESTAR INSTÁVEL - O VIRAR-BRANCO PARQUE-XINGUANO ${ }^{19}$}

Karu, um homem de cerca de 50 anos, filho de pai kuikuro e mãe yawalapiti que está em Canarana há quase uma década, costumava me narrar diferentes histórias que culminavam em sua vinda para a cidade. A razão dele estar em Canarana podia ser traçada de múltiplas maneiras, quase todas envolvendo feitiços, e ele as me narrava espontaneamente quando eu lhe perguntava sobre sua vida em Canarana. Em uma de nossas conversas, ele me disse que quando sua mulher foi enfeitiçada na aldeia, adoeceu e perdeu os movimentos das pernas, ele teve de trazê-la para a cidade. Perguntei, com certa ingenuidade, porque ele não a tratou no PIX, com pajelança. Karu se sentiu ofendido. Respondeu com braveza que a cadeira de rodas não é feita para o chão de terra da aldeia, e que a doente precisaria de ajuda para tudo, para ir no mato defecar, para levantar-se da rede e comer, para banhar-se. O caso era grave, a mulher fez pajelança e não se curou de pronto e tanto o tratamento dos pajés, quanto o dos médicos seria lento. Ser doente é mais difícil na aldeia. Na cidade - esbravejava Karu - há vaso sanitário e chuveiro dentro de casa, aparelhos para fazer exames, remédios que aliviam a dor. Ele não teve outra opção a não ser mudar-se para Canarana.

Pouco tempo depois, sentados na mesma mureta, Karu contou-me outra história que justificava sua vinda. Disse que vivia na aldeia e que lá sua família toda morreu. A família toda eram seus pais - a esposa, os tios, os irmãos, e os filhos destes todos, estavam vivos. Toda morte no alto Xingu é atribuída a feitiço e terem morrido seu pai e sua mãe em tão curto espaço de tempo era mais uma prova de que eles eram vítimas de um feiticeiro cruel. Com a morte da família - da família "inteira" - Karu ficou louco e foi para Canarana. "Fiquei louco. Fiquei triste; os índios falam assim, 'fiquei louco', explicou-me. No PIX, os médicos brancos tendem a entender - e a tratar-os indígenas "loucos" com remédios para depressão, por isso a tradução que Karu me fazia: "vocês dizem tristeza, nós dizemos loucura"20. A loucura de Karu implicava a perda do arbítrio frente à situação. Ele não escolheu vir para Canarana, ele ficou louco. Narrativas como essa
19 Nesta seção, os nomes próprios foram alterados para resguardar a identidade de meus interlocutores.

20 O psicólogo do Distrito Especial de Saúde Indígena, responsável pelo acompanhamento dos pacientes psiquiátricos no PIX, disse-me, certa vez, que em quase todas as aldeias do Parque existem pacientes em tratamento psiquiátrico, com antidepressivos e estabilizadores de humor. 
remetem à "loucura" como um gatilho de movimento, um impulso que já nasce fora do controle, pois é marcado pela incapacidade de arbitrar. Tudo se passa como se o pulso que advém da loucura não tivesse direção. Em narrativas similares, em que me diziam da "loucura" gerada pela morte de um parente querido, os parque-xinguanos enumeravam os lugares por onde passaram quando estavam "loucos", aldeias e cidades do entorno, até se estabelecerem em Canarana. Nesses casos, estar ali não implicava ver-se fixado à cidade: Canarana era mais uma etapa de um movimento descontrolado.

O esforço em justificar a sua presença na cidade é um ponto importante que conecta essas e tantas outras conversas que tive com os parque-xinguanos em Canarana. Basicamente, Karu me dizia que as razões para ele estar ali eram razões propriamente indígenas: a família, a feitiçaria e a "loucura”, a que os brancos chamam depressão. Isso tudo implicava um acúmulo de relações índias em seu corpo que the permitiria retomar sua indianidade quando bem pretendesse. Eu perguntava como era sua vida na cidade e ele me respondia narrando os motivos que o levaram a deixar a aldeia. $O$ estado fenomenologicamente dado naquelas conversas, seu "contexto convencional", para usar os termos de Wagner apropriados por Kelly (2005), era que ele estava na cidade, onde nos víamos todos os dias e onde Karu morava há quase uma década. O discurso vinha construir seu desejo de voltar para a aldeia, firmando sua agência e intenção como direcionadas para o polo indígena da dualidade virar-branco versus virar-índio que os parque-xinguanos punham em jogo nestas conversas. O dado era o virar-branco, afinal a vida na cidade impõe uma moralidade, uma língua, uma estética e um corpo genericamente brancos, que independem das diferenciações desta categoria. O que ele tinha que construir intencionalmente naquela conversa era sua indianidade, sua capacidade e seu desejo de voltar para o PIX, lugar por excelência do virar-índio. Esta indianidade, por ocupar aqui o espaço da invenção, nada podia ter de genérica: era preciso determinar que tipo de índio Karu estava virando, pois isso implicaria construir afecções bastantes diferentes.

Karu não era o único parque-xinguano que negava morar em Canarana a despeito de estar ali durante toda minha estadia no ano de 2014, e que vinculava seu discurso sobre a cidade às razões pelas quais ele teria deixado a aldeia. De fato, essa organização da narrativa era bastante comum. Outro indígena que vivia essa situação, um homem matipu de menos de 30 anos, teorizou, certa vez, sobre a distinção entre moradores e não-moradores indígenas em Canarana. Afirmava ele que a diferença estava na razão pela qual o indígena se mantinha na cidade: se fosse por necessidade (casos de doença e feitiçaria, exercício de um cargo público, representação política e acesso à educação branca com vistas a ajudar a comunidade, ou seja: questões que misturam numa mesma ideia a ma- 
nutenção da integridade física e a valorização da tradição), o indígena não era um morador; se fosse sem necessidade (entenda-se, por querer, desejo pessoal), ele era sim um morador. Além disso, essas razões tinham um efeito crucial sobre a capacidade do sujeito de desejar voltar: os que estão na cidade "por necessidade" retornam para a aldeia quando podem ou querem, os outros, são incapazes de fazê-lo ou mesmo de desejar fazê-lo. O jovem estava ali há quase dois anos, cursando o Ensino Médio para depois voltar e "ajudar a comunidade"-ele me dizia não ser um morador.

A falta de opção é outro ponto importante a conectar as histórias que Karu me contou ao longo do ano de 2014, para justificar sua vinda para Canarana. Muitas vezes, ao fim da narrativa, eu Ihe fazia perguntas sobre como era viver na cidade, e nessas ocasiões Karu me dizia que não morava ali, que pretendia voltar para a aldeia e que só estava ali por que sua mulher e ele estavam doentes - Karu mancava um pouco por conta de uma dor nas pernas, e a história de sua doença era mais uma das histórias que justificavam sua vinda para Canarana. Ele tinha boas razões para estar em Canarana naquele momento e ele ia voltar para sua aldeia no PIX: ele não era um morador da cidade. Nenhum parque-xinguano em "sã consciência" vai para a cidade sem um bom motivo. Em consonância com a teoria do jovem matipu, Karu me dizia não morar na cidade. Em alguns contextos, dizia ter um bom motivo para estar ali, noutros, dizia que sua consciência não estava sã quando ele deixou a aldeia.

Poucos meses antes, este mesmo jovem matipu que teorizava sobre o morar na cidade me dissera que não desejava voltar para a aldeia, contrariando o que me relatava agora sobre seu desejo de voltar e ajudar a comunidade. Dissera que seu sonho era cursar a faculdade de medicina, formar-se e viver em outra cidade, trabalhando como médico - Canarana, dizia, tinha "índios demais". Poderia até mesmo trabalhar com indígenas, mas não no PIX. "Ninguém nunca me apoiou [referia-se a seus parentes da aldeia], nunca me mandou dinheiro, nunca me mandou nada. Eu estou aqui sofrendo e ninguém pensa me ajudar", refletia, com rancor. A falta de apoio era, naquele contexto, uma indicação de que seus parentes negligenciavam suas relações de parentesco com ele. Sem algo que o fizesse voltar, o jovem matipu sonhava com uma vida autônoma, como médico, do lado de fora do PIX e do lado de fora de Canarana. Sonhava com outras relações que não aquelas da aldeia, que não aquelas dos seus "maus-parentes". $\mathrm{Na}$ América indígena o parentesco não é um dado, e para se ter parentes é preciso fazer parentes (cf. por exemplo, Viveiros de Castro, 2002; Vilaça, 2002). Tudo indicava que o parentesco do homem matipu vinha passando pelo processo oposto, vinha sendo desfeito.

$O$ dado deste contexto era, assim como em minha conversa com Karu, que estávamos na cidade, mas nessa cidade com "índios demais" - Canarana aqui 
me era apresentada como o polo indígena da dualidade virar-índio versus virar-branco. Ele fixava suas más relações com os parentes índios como dado e esse valor gerava uma continuidade entre a aldeia e Canarana. Ambas, por terem "índios demais", não lhe interessavam. Seu discurso se aplicava então a construir um futuro noutra cidade, pelo afastamento dos parentes índios, pela permanência junto aos brancos, pela falta de desejo de voltar. Nesse contexto em que o espaço da invenção está ocupado pelo polo branco da dualidade (virar-)branco versus (virar-)indígena, é preciso diferenciar o tipo de branco que se deseja ser, pois cada um destes tipos, como vimos, se define por afetos bastante diferentes. O desejo do jovem matipu estava vinculado à posição específica de médico na cidade, não apenas à cidade.

A especificidade do branco, sua divisão em "peões" ou "chefes"/"doutores", recoloca a questão da indianidade por mediação. O valor de doutor ou chefe nesse contexto não coincide com o valor destas posições no mundo branco: da perspectiva indígena, o branco de valor, chamado de chefe ou doutor, é aquele que pode ajudar o índio. Estes são os brancos que constroem as relações mais produtivas com os índios, que agem com generosidade, que podem, portanto, construir parentesco com eles. Os brancos "de verdade" que passaram no Xingu foram os irmãos Villas-Bôas, chefes pela perspectiva indígena, mediadores dos povos, influentes, falantes de bom português e aptos a lidar com a política de papel do mundo de fora. Quando morreram, foi realizado um quarup, grande ritual alto-xinguano restrito aos chefes indígenas mortos. Os Villas-Bôas foram homenageados por serem chefes de índios. O caráter indígena da categoria de "branco de verdade", de "doutor", reforça outra vez o fundo indígena desta teoria do virar-branco e exige que recordemos que mesmo termos em português, quando apropriados pelos indígenas precisam ser tomados como conceitos nativos, e deslocados de nossos automatismos significadores.

Em ambos os caminhos, o que temos são índios. Índios virando brancos à maneira indígena na cidade e índios virando índios (não-peões) assim também. Anti-mestiçagem ${ }^{21}$. Na síntese de Viveiros de Castro,

21 Para mais sobre antimestiçagem ver Kelly (2016)

\begin{abstract}
O anti-mestiço como ideal dos povos indígenas que se confrontam com a pressão modernizadora eurocêntrica éo do ente antropológico que é índio e branco ao mesmo tempo — mas é índio, pois a teoria da transformação que está operando aqui é uma teoria indígena, não branca, uma teoria, justamente, que pressupõe a recusa do Um, do Estado que se constitui pela desconstituição dos povos sob sua totalização transcendente (2015a: 11).
\end{abstract}

Cabe lembrar a já referida colocação do líder kawaiweté, que substancializa uma máxima da vida parque-xinguana em Canarana: aqueles que não conseguirem 
ser autônomos na cidade, nem sofrer ali orientando-se para a aldeia, devem voltar. Ou seja, os índios que não conseguirem virar-brancos com controle e autonomia indígenas, ou virar-índios por reforço de sua relação com os parentes do PIX, devem ser índios pela aldeia mesmo, que nesse contexto serve de macro definidor da indianidade.

Morar ou não morar em Canarana é uma questão que se define a cada contexto relacional, podendo variar nos discursos de uma mesma pessoa, em alguns contextos coincidindo com a questão do virar-branco. $O$ fato da temática do virar-branco manifestar-se entre os parque-xinguanos nos juízos sobre quem "volta para a aldeia", evidencia ainda mais que a comparação se dá sob o pano de fundo do universo indígena e que ela é específica ao contexto citadino. Era sempre possível dizer que a pessoa x não volta em relação à pessoa y (pois o motivo de $y$, para estar na cidade, seria melhor que o de x); e que z não volta em comparação com x. A capacidade de "voltar", nesse contexto, atenta para o controle sobre a transformação em jogo na experiência da cidade, e para a manutenção da autonomia do sujeito no decorrer deste processo. Dizer-se não-morador era uma forma de reafirmar seus laços com a aldeia, marcando que voltaria, sempre, às vezes ou definitivamente; sobre um indígena que já não "acostumava mais com a aldeia", dizia-se que ele não volta - algo que algumas vezes me foi traduzido, literalmente, como virar-branco.

O morador seria, pois, aquele que se transforma em direção aos brancos, ao passo que o não-morador seria aquele que se transforma em direção aos índios. A cidade é um dado para ambos, mas a posição que ela ocupa no escopo da dualidade índios versus brancos é variável. Quando a invenção se orienta para o virar-índio, o que temos é um movimento direcionado ao parentesco, à própria humanidade, e havendo muitos índios diferentes, o que se pretende é sempre um virar-índio-específico, falante de uma determinada língua, com costumes singulares, com uma dieta particular. O branco a que se opõe, por sua vez, é um branco genérico, em relação ao qual a questão de sua diferenciação interna não se coloca. O que essa teoria da transformação dos parque-xinguanos na cidade de Canarana enfatiza é que o mesmo se passa com o virar-branco, que deve ser um virar-branco específico, um virar-branco-chefe, branco-sem-sol, doutor. Apenas esta transformação interessa aos indígenas e este interesse está diretamente vinculado à preservação da autonomia sobre si. O desejo parque-xinguano de virar-branco-chefe indica o desejo de controlar sua transformação, recusando a posição de peão, a despeito de sua ocupação laboral.

Quando o líder kawaiweté diz que os índios não podem sair para a cidade para assumir trabalhos de peão, subentende-se ali que sair para ser "doutor" é uma opção valorizada. O "chefe"/"doutor" é um ser autônomo: e mantida a autonomia, o índio continua capaz de controlar a própria transformação e assim, 
voltar quando quiser, se quiser, para a aldeia. Mas a despeito do caráter relacional destes juízos, da ênfase na autonomia dos sujeitos como essencial para a condução das transformações intencionalmente guiadas pelo espaço inventivo, e como variável importante para atribuição de valor positivo àquilo que seria virar-índio e virar-branco, os parque-xinguanos sabem que para os brancos, mesmo no contexto da política indigenista, virar-branco é invariavelmente negativo.

Pereti Suyá, quando presidente da ATIX, costumava dizer para os outros indígenas que trabalhavam com ele nessa associação, que era importante aprender o português, mas que eles não deveriam aprender "muito", ou os brancos assumiriam que tinham "virado branco". Os brancos entendem o virar-branco dos índios como uma perda da autonomia sobre si. Para fazer ver sua autonomia, a proposta de Pereti era enfraquecer o caráter branco de sua presença ali, falando um mal português. Essa não é única alternativa possível e, outras vezes, vi indígenas optarem por intensificar sua indianidade, vestindo-se com ornamentos tradicionais, solicitando um tradutor e falando na língua indígena, ainda que dominem o português. Se, no contexto político, os brancos só veem autonomia nas posições de índio, os parque-xinguanos têm que se mostrar índios, sob o risco de serem tomados aqui como índios-virados-brancos sem autonomia, como índios-peões, como brancos-menores, como presas. A perspectiva dos brancos é aqui fundamental, pois se os brancos assumirem que os índios são brancos, eles Ihe retirarão as terras, e seus direitos diferenciados se extinguirão. Por essa razão, o líder kawaiweté cuja fala encerrou a sessão anterior deste trabalho, temia tanto que os brancos tomassem os parque-xinguanos por "miseráveis". Se os brancos passarem a tomar os índios como brancos, e nos olhos dos brancos todo virar-branco é virar pobre, a consequência mais provável é que eles tenham de se tornar, ou mesmo já se tornado, miseráveis ou peões - mas eles lutarão com todas as suas armas para evitar que isso aconteça.

\section{INCONGRUÊNCIAS}

Desde a perspectiva citadina parque-xinguana, a relação ideal com alteridade é uma relação marcada pela simetria de posição dos sujeitos, que potencializa suas diferenças e agrega potências - algo que, por acrescer sua pessoa, aumenta também seu prestígio. Mas essa relação ideal não pode ser atualizada na posição de "peão", que encarna a alteridade enfraquecida na cidade, carente de autonomia sobre si. Desde os Villas-Bôas, os brancos por excelência são os chefes, duplamente brancos, como assinalei, e é com eles que os parque-xinguanos pretendem entreter relações em posição de simetria. Essa é uma possibilidade que o Estado brasileiro não concebe: os índios deveriam virar trabalhadores, brancos de segunda classe, não indígenas de prestígio, tampouco, brancos patrões. Eis o 
que o capitalismo lhes tem a oferecer. A potência criativa que os permite quererem se colocar em simetria com a diferença dos brancos doutores, e a forma de estar no mundo que esta criatividade implica, é o ponto chave para essa discussão. As determinações do Estado negam a incomensurabilidade de princípio que existe entre indígenas e brancos e preveem que a diferença indígena, quando for uma diferença "em presença" e não isolada, deve ser assumida como uma diferença de classe. Mas, entre índios e brancos, aquilo "que é compartilhado não pode ser concretizado como aquilo que elas [eles] têm em comum, a não ser a relação entre elas [eles]" (Strathern, 2006 [1988]: 88). A desigualdade social pela qual o Estado vem definir estes sujeitos tem por premissa uma igualdade de interesses que é absolutamente falsa, e que encobre com crueldade uma diferença inerente às partes. $O$ único ponto comum possível entre brancos e índios é a relação que há entre eles: e isso já é muito.

A matemática integrativa do Estado reza que índios estariam para brancos, da mesma maneira como pobres estariam para ricos. A violência do Estado capitalista é uma questão colonial: imposição de uma forma, ímpeto de unificação. Mas a equação traz um erro bruto, que não está na transformação que ela apresenta. O erro é, antes, que ela comensura o incomensurável, pois a não comensurabilidade entre índios e brancos não implica a impossibilidade de transformações entre eles, uma vez que a ontologia ameríndia é uma ontologia do devir. "Peões" e "doutores" são uma oposição que só pode existir como subdivisão da categoria do virar-branco, e o virar-branco só pode existir dentro de uma teoria indígena da transformação: virar-branco é coisa de índio. Ao menos desde as mitológicas de Lévi-Strauss é bem sabido que, nos mitos ameríndios, seres muitos diferentes se transformam uns nos outros, seres incomensuráveis, que compartilhavam apenas as relações que travavam entre si. A existência de relação como uma condicional é tão mais interessante para pensar essas transformações - e aquelas entre índios e brancos - que o pressuposto de continuidade, seja de um construto teórico, um esquema ou um metaesquema. Não é preciso que haja um algo comum para haver transformação: ao contrário, é preciso haver diferença, "e nenhuma diferença é indiferente, pois toda diferença é imediatamente relação" (Viveiros de Castro, 2002:164) - máxima das já referidas mitológicas de Lévi-Strauss.

Se indianidade é, da perspectiva branca, uma pobreza, a pobreza é, da perspectiva indígena uma falta de autonomia. A autonomia é o signo das relações inventivas no PIX, por isso, no dado da cidade, Kuruaravi se aplicava a me dizer como ele era autônomo, tinha controle sobre si, e tinha relações acumuladas com seus parentes - ele construía para mim sua indianidade autônoma, mesmo num meio que tende sempre a posicioná-lo como "peão". A diferença entre índios e brancos (estes, escalonados pelo Estado entre brancos de muita, pouca, ou nenhuma renda) é uma diferença intensiva, de outra ordem que aquela entre 
pobres em ricos que só se distinguem pela extensão de uma alcunha capitalista. Todavia, não só a política atual demanda a distinção molecular destas categorias - a violência contra essas populações e os retrocessos constitucionais são claras demonstrações da ofensiva anti-indígena que caracteriza o atual cenário brasileiro-, como também os indígenas em Canarana parecem reivindicar que, frente às suas identidades dispersivas, seja reconhecido um princípio crucial: a cada nível fractal de atualização desta diferença, indígenas e brancos se definem de maneira exclusiva e intensiva, e este ponto é-lhes basilar.

Por isso também Pereti destacava a importância de falar bem o português, mas não tanto. Os indígenas já se dão conta de que os brancos não entendem os seus conceitos, e para comunicar-se eles usam de seus corpos, moldam-nos de maneira burlesca se preciso for. No contexto da política dos brancos, os índios atualizam sempre o seu caráter político, convencional e autônomo: os índios viram-índios. Tal afirmação se faz evidente no contexto parque-xinguano na cidade de Canarana, onde a questão de virar-branco é mensurada pela partição deste conceito em outras duas outras posições possíveis, a de "peão" e a de "doutor"-e "doutor", por ser autônomo, incorpora o indígena magnificado pela alteridade branca, ao passo que "peão", por não o ser, incorpora o branco improdutivo, sem relação com os indígenas (tudo isso, obviamente, como derivações de um afeto índio primeiro). $O$ adjetivo que acompanha a invenção do virar-branco é tão ou mais importante que o branco genérico em si: um branco "chefe" é um branco ideal, cuja posição se pode almejar e se almeja; um branco "peão" é um branco cuja posição é recusada, e se evita ao máximo. Existem inúmeros dispositivos para não se deixar o pior acontecer: os índios podem voltar à aldeia; podem andar bem vestidos na cidade; podem portar-se como índios ou portar-se como chefes. Mesmo com todas as precauções, com todas as manobras políticas, com a imagem asseada e mansa que os índios tanto se esforçam em passar, os brancos seguem rejeitando a simetrização de posição entre seus chefes e os parque-xinguanos. Mas os indígenas não desistem.

O Estado tampouco recua e seus movimentos para validação desta equação seguem avançando, arrastando consigo alguns sujeitos, e empurrando outros para as beiradas. Os benefícios sociais são talvez a mais explícita ofensiva estatal para reduzir os índios a pobres: após fazer os documentos de identidade, e se firmar brasileiro, é preciso cadastrar-se no Cadúnico e classificar sua família como de baixa renda. Não pretendo afirmar aqui, de maneira alguma, que não deve haver benefícios sociais voltados aos índios; mas sua diferença exige políticas públicas também diferenciadas, debatidas nas particularidade dos sujeitos a que se destinam e não apenas pela extensão de programas já existentes, pautados na ideia de brasileiro médio, que é o brasileiro pobre. A pauperização da diferença é a grande arma de guerra do Estado brasileiro. 


\section{CONCLUSÃO}

Parece-me claro que o simples desejo parque-xinguano de existir na cidade de maneira autônoma, subverte uma série de lógicas binárias impostas pelo universo citadino, a começar com aquela da epígrafe deste trabalho que pauta em suas entrelinhas que índios são isolados ou integrados - e por integrados, pretende uma classe de branco inferior, entenda-se, de branco pobre. Mas não só. O desejo parque-xinguano trai o discurso da ex-ministra Kátia Abreu, mas trai também as fronteiras de um dos grandes divisores sobre o qual se erige a disciplina antropológica, aquele entre "nós" e "eles". Canarana é mais um dentre tantos espaços compartilhados por sujeitos marcados por diferenças intensivas e irredutíveis, espaços que se multiplicam no Brasil. Como consequência, a distinção conceitual entre os sujeitos é forçada a pautar-se em outros critérios que aqueles da geografia que remontam às origens coloniais da disciplina e cujo rendimento já está, há muito, exaurido. Doutra parte, a ofensiva do Estado no sentido de reduzir a diferença indígena a uma questão de classe, subverte também a lógica alto-xinguana, e refirma o grande divisor. Em presença, toda diferença não passa de desigualdade, repete sem cessar a máquina estatal.

Não há mais onde conjurar a diferença: ela está no seu país, no seu estado, na sua cidade, na casa ao lado - talvez ela esteja dentro de casa, talvez ela esteja em você. O quão mais complicado se torna dizer quem é "diferente" e quem é "igual", menos porque os "diferentes" descem ladeira a baixo e mais porque finalmente começamos a reconhecer que nossos vizinhos e colegas de trabalho não eram, assim, tão iguais a nós, mais urgente se coloca a questão de Lima que abre as interrogações deste trabalho: como fazer uma antropologia da alteridade em presença? A resposta vem sendo construída nas etnografias, que se voltam cada vez mais a essas questões, e dão mostras de que a antropologia é capaz de aplicar-se a descolonizar seus conceitos e a engajar-se também na luta pela descolonização de seus sujeitos-objeto. Este artigo pretendeu caminhar nessa direção, contribuindo para os trabalhos antropológicos descolonizadores de si-de seus conceitos, esquemas e matemáticas disciplinares - e dos outros.

A pergunta de Lima requer, no entanto, mais que uma solução pragmática. Ela ressoa questões sobre como fazer uma antropologia política, sem para isso ceder aos discursos do maquinário estatal; sobre como dizer de modos de existência relacionais e transformativos, sem permitir que sua diferença se dissolva em ideias de pluralidade nacional; sobre como lidar com a necessidade jurídica de definições positivas sobre o quem é indígena-quilombola, ribeirinho, e outros grupos minoritários - sem para isso condená-los às amarras de um conjunto de diacríticos. Para uma antropologia que se esforça em 
aliar-se aos indígenas e fazer coro às suas questões, estas são indagações de primeira importância, dada a violência com que o Estado brasileiro lida com aqueles que insistem em se definir à margem das definições estatais.

No Xingu, e mais especificamente na cidade de Canarana, o duelo já se instaurou - de um lado, os parque-xinguanos trazem a estratégia da simetrização, recusando uma inserção compulsória no sistema capitalista que lhes usurpa a autonomia; outra, a do desejo estatal, se dedica a dominar o sujeito indígena, subjugá-lo e assim sagrar-se predador diante de sua presa. A verdadeira paz parque-xinguana se dá pela simetria de posição entre os sujeitos, a do Estado só pode se dar na vitória contra a diferença indígena. Uma situação impossível. Um dos lados terá de ceder. Lutemos, então, para que não sejam, mais uma vez, os índios.

Amanda Horta é doutoranda do Programa de Pós-Graduação em Antropologia Social do Museu Nacional da UFR]. Desenvolve pesquisa etnográfica na cidade de Canarana (MT) junto aos indígenas do Parque Indígena do Xingu.

\section{REFERÊNCIAS BIBLIOCRÁFICAS}

CARDOSO DE OLIVEIRA, Roberto

1968 Urbanização e tribalismo. Rio de Janeiro, Jorge Zahar.

GUERREIRO, Antônio Roberto

2008 Parentesco e aliança entre os Kalapalo do Alto Xingu.

São Carlos, dissertação, UFSCar.

2012 Ancestrais e suas sombras: Uma etnografia da chefia

kalapalo e seu ritual mortuário. Brasília, tese, UnB.

GOW, Peter

1991 OfMixed Blood. Kinship and History in Peruvian

Amazonia. Oxford, Clarendon Press.

HECKENBERGER, Michael

2001 "Estrutura, história e transformação: a cultura xinguana na longue durée, 1000-2000 D.C". In FRANCHETTO, B. e HECKENBERGER, M. (orgs.). Os povos do Alto Xingu. História e cultura. Rio de Janeiro, UFR]. 
IBCE

2010 Os indígenas no Censo Demográfico 2010 primeiras considerações com base no quesito cor ou raça. Disponível em: http://www. ibge.gov.br/indigenas/indigena_censo2010.pdf

KAMAIURÁ, Kanawayuri

2011 "Relatos indígenas. 'O contato com os brancos". In Almanaque Socioambiental. Parque Indígena do Xingu, 50 anos, p.49.

KELLY, José Antonio

2005 "Notas para uma teoria do 'virar branco"'. Mana, 11 (1): 201-234.

2011 "Políticas indigenistas y anti-mestizaje indígena em Venezuela". In: BELLO, Luis (org.). El estado ante la sociedad multiétnica y pluricultural: Políticas públicas y derechos de los Pueblos Indígenas em Venezuela (1999-2010). Copenhague, IWGIA, v. 1.

2016 Sobre a anti-mestiçagem. Tradução de Nicole Soares, Levindo Pereira e Marcos de Almeida Matos. Curitiba, Desterro. Species - Núcleo de Antropologia Especulativa. Florianópolis, Cultura e Barbárie.

MENEZES, Maria Lúcia Pires

2000 Parque Indígena do Xingu: a construção de um território estatal. Campinas, Unicamp.

NUNES, Eduard

2010 "Aldeias urbanas". Espaço Ameríndio, Porto Alegre, v. 4, n. 1.

2012 No asfalto não se pesca. Parentesco, mistura, e transformação entre os Karajá de Buridina (Aruanã-CO). Brasília, dissertação UnB.

PEIRANO, Mariza

2002 "This Horrible Time of Papers". Documents and National Values (em inglês e português). Série Antropologia 312. Brasília, UnB.

2009 "O paradoxo dos documentos de identidade: relato de uma experiência nos Estados Unidos". Horizontes Antropológicos, 32: 53-80.

PITARCH, Pedro

2010 The Jaguar and the Priest: An Ethnography of Tzeltal Souls. Austin, University of Texas Press. 
RODARTE, lanaculá

2010 Estratégias de gestão ambiental no Parque Indígena do Xingu. Canarana, trabalho de conclusão de curso, Universidade Norte do Paraná.

SCHWARTZMAN, Stephan etal.

2013 "The Natural and Social History of the Indigenous Lands and Protected Areas Corridor of The Xingu River Basin".

Philosophical Transactions of the Royal Society.

STRATHERN, Marilyn

2006 [1988] Ogênero da dádiva. Campinas, Unicamp.

SUYÁ, Tempty

2011 "Relatos indígenas. 'O contato com os brancos". In: Almanaque Socioambiental. Parque Indígena do Xingu, 50 anos, p. 48-9.

VILAÇA, Aparecida

2000 "O que significa tornar-se outro? Xamanismo e contato interétnico na Amazônia". Revista Brasileira de Ciências Sociais, vol. 15, n. 4: 56-72.

2002 "Making Kin Out of Others in Amazonia". The Journal of the Royal Anthropological Institute, vol. 8, n. 2: 347-365.

2015 "Dividualism and Individualism in Indigenous Christianity. A Debate Seen from Amazonia". Hau: Journal of Ethnographic Theory, 5 (1).

VIVEIROS DE CASTRO, Eduardo

2002 "O problema da afinidade na Amazônia". In: A inconstância da alma selvagem. São Paulo, Cosac Naify.

2009 "Claude Lévi-Strauss por Eduardo Viveiros de Castro". Entrevista. Estudos Avançados, v. 23, n. 67.

2015a Prefácio. "O índio em devir". In HERRERO, M. e FERNANDES, U. (orgs.). Baré: povo do rio. São Paulo, Edições Sesc.

2015b "Sobre os modos de existência dos coletivos extramodernos: Bruno Latour e as cosmopolíticas ameríndias". Projeto de Pesquisa.

WAGNER, Roy

2010 [1981] A invenção da cultura. São Paulo, Cosac Naify.

WEST, Paige

2006 Conservation Is Our Government Now: The Politics of Ecology in Papua New Guinea. Durham, Duke University Press. 


\section{ABSTRACT}

This paper proposes an approach to the park-xinguan indigenous peoples from the city of Canarana (MT), a municipality that composes the southeast portion of the Xingu National Park (in portuguese, Parque Indígena do Xingu, PIX). Hosting the main institutions of social care, the regional FUNAI and several branch offices of indigenous organizations, Canarana is a city of reference for PIX's indigenous peoples. The city is ruled by a logic that insists on compressing the indigenous under the image of the poor, and each day it is also more filled with park-xinguans. These facts challenge the indigenous existence and philosophy, and result in an absolutely creative moment in the life of these people, of their philosophical practices and imagination. Starting from my experiences in Canarana from 2014 to 2016, this paper explores two different images of the white men from the city formulated by the park-xinguan indigenous peoplethe "peon" and the "chief" - highlighting the consequences of the complexification of these category to the indigenous theory of transformation. Lastly, it turns to the indigenous movements and expectations for their relations with different white men from the city, and proposes a reflection about some of the most salient incongruities between the park-xinguan perspective and the ways in which the Brazilian State intent to update this relations in the urban landscapes of the municipality.

Recebido em 23 de agosto de 2016 Aceito em 15 de dezembro de 2016.

\section{KEYWORDS}

Indigenous Ethnology, Xingu, Indigenous in the City, Creativity, Relations with the Whites. 